\title{
Comparison of Diagnostic Accuracy of BIRADS Score With Pathologic Findings in Breast Lumps
}

\author{
Navya B N ${ }^{1 *}$, Shalu Thomas ${ }^{1}$, Rudresh Hiremath ${ }^{2}$ and Sathyavathi R Alva ${ }^{1}$ \\ ${ }^{1}$ Department of Pathology ,K V G Medical College and Hospital, Karnataka, India \\ ${ }^{2}$ Department of Radiology, K V G Medical College and Hospital, Karnataka, India
}

\begin{abstract}
Background: Breast lump is one of the commonest complaints with which patients present in breast clinics. As approximately $10 \%$ of breast masses ultimately lead to a diagnosis of breast cancer, it is important for women with a breast lump to receive appropriate evaluation. A confident diagnosis can be made in $95 \%$ of the cases through a combination of clinical examination, imaging and fine needle aspiration cytology. Histopathology is the gold standard for diagnosis.

Methods: This is a prospective study conducted in the Department of Pathology, K.V.G Medical College, Sullia on 50 patients who presented with clinically palpable breast lump. Patients were subjected to sonomammography and Breast Imaging Reporting and Data System (BIRADS) scoring followed by FNAC and histopathological examination. Sensitivity, specificity, accuracy, positive and negative predictive values of sonomammogram in relation to the BIRADS score and FNAC taking histopathology as the gold standard was calculated.
\end{abstract}

Result: FNAC had significantly higher sensitivity, specificity, positive and negative predictive values and accuracy compared to sonographical diagnosis using BIRADS score.

Conclusion: FNAC could be considered as the first method to evaluate breast lesions, recognized by means of imaging techniques.

Keywords: BIRADS, Fine-needle Aspiration Cytology, Histopathology

\section{Introduction}

Breast masses are localized swellings that feel different from the surrounding breast tissue. It is a symptom/sign for a variety of conditions. ${ }^{[1]}$ Breast lump is one of the commonest complaints with which patients present in breast clinics. ${ }^{[2]}$ As approximately $10 \%$ of breast masses ultimately lead to a diagnosis of breast cancer, it is important for women with a breast lump to receive appropriate evaluation. ${ }^{[1]}$ Breast cancer is increasingly common in women worldwide. It is one of the leading causes of death among female malignancies. The incidence varies from region to region, more in developed countries $(>80$ per 100,000 populations) than in developing countries ( $<40$ per 100,000 populations). ${ }^{[3]}$ It commonly affects women older than 40 years of age. However, younger women can also be affected. Its management requires a multi-dimensional approach and a collaboration with different specialists. An accurate evaluation can maximize cancer detection and minimize unnecessary testing and procedures. Early detection and treatment is a key to preventing breast cancer from spreading. ${ }^{[4]}$

A confident diagnosis can be made in $95 \%$ of the cases through a combination of clinical examination, imaging (including mammogram and/or sonomammogram) and fine needle aspiration cytology (FNAC) ${ }^{[1]}$ Mammography is cost efficient and widely accepted technique to evaluate clinically suspected breast lesions and used for screening of breast cancer. High resolution sonography is a useful adjunct modality and helps characterizing a mammographically non-detected palpable abnormality, especially in dense breast. ${ }^{[5,6]}$ Sonomammography is noninvasive, easily available, cheaper and accurate tool in diagnosing breast masses. It is very helpful in pre surgical assessment of tumor size of even $2 \mathrm{~mm}$. It is the method of choice for differentiating solid from the cystic lesions, for further characterizing mammographic findings and better appreciating palpable breast lesions..$^{[1]}$

The American College of Radiology (ACR) created the breast imaging reporting and data system (BIRADS), to achieve trick verbal uniformity so as to get clear, unambiguous and standard language, not only among radiologist but also the treating physicians and surgeons. BI-RADS had 0-6 assessment categories. ${ }^{[6]}$

$\checkmark$ Category 0: need additional imaging evaluation

$\boldsymbol{\sim}$ Category 1: negative

$\checkmark$ Category 2: benign finding

$\checkmark$ Category 3: probably benign finding; short-interval follow-up suggested 
$\checkmark$ Category 4: suggestive abnormality; biopsy should be considered

$\checkmark$ Category 5: highly suggestive of malignancy; appropriate action should be taken

$\checkmark$ Category 6: known biopsy-proved malignancy

FNAC has a high diagnostic accuracy rate (98.9\%) in the hands of experienced cytopathologists. FNAC is a reliable method to differentiate whether a suspicious breast mass is benign or malignant. ${ }^{[1]}$ In addition to its high diagnostic accuracy FNAC offers advantages such as minimal invasiveness, minimal discomfort, cost effectiveness and rapidity of results. FNAC is therefore an extremely vital tool in the evaluation of palpable breast lumps especially in resource limited settings. ${ }^{[7]}$

However, the aspiration cytology is not a substitute for conventional surgical histopathology as a definitive diagnosis is not always possible by cytology, but categorization of disease and differential diagnosis can be provided in the majority of cases. ${ }^{[8]}$

In the present study we aim to compare the diagnostic accuracy of BIRADS score in detecting benign and malignant lesions with pathological findings (FNAC and Histopathology) which is used for the final diagnosis in patients presenting with breast lumps, thus helping in avoiding unnecessary surgical procedures.

\section{Materials and Methods}

This was a prospective study conducted in the Department of Pathology, K.V.G Medical College, Sullia on 50 patients who presented with clinically palpable breast lump. The term "palpable breast lump" meant an area of denser breast tissue felt different from the surrounding tissue. Samples for the study were selected according to the inclusion and exclusion criteria.

\section{Inclusion Criteria}

- $\quad$ Female patients of all ages with complaints of breast lump.

- $\quad$ Patients who have underwent breast imaging (including BIRADS scoring) and pathologic examination (i.e., both FNAC and histopathology).

\section{Exclusion criteria}

- Patients with recurrent lumps, history of prior irradiation to the chest or breast and cystic breast lesions

- $\quad$ Pregnant and lactating ladies

- Male patients

The clinicians obtained a full history, performed breast examination, and then the patients were sent for sonommamography to the radiology department.
Sonommamography was performed on all cases presenting with breast lump. The images obtained were analyzed and categorized using the BIRADS score as benign and malignant. For the next part of the study, all the patients were subjected to FNAC and later on followed up with histopathology (Excision biopsy/Mastectomy specimens) findings which was used as the gold standard to confirm the diagnosis on sonomammography according to BIRADS classification and FNAC.

FNAC was performed using a $23 \mathrm{G}$ needle attached to $10 \mathrm{~mL}$ disposable plastic syringes, smeared on standard microscope glass slides and stained with haematoxylin and eosin (H\&E) and Leishman stain. The slides were reviewed under light microscopy. For histopathological examination the tissue was fixed in $10 \%$ formalin and sections were taken from representative areas. The samples were labeled and processed, which involves a series of steps lasting 12 -16 hours. The slides were then stained with routine haematoxylin and eosin and examined under the microscope for histopathological diagnosis.

Statistical analysis were performed to compute the sensitivity, specificity, accuracy, positive and negative predictive values of sonomammogram in relation to the BIRADS score and FNAC taking histopathology as the gold standard.

\section{Results}

The study included 50 patients presenting with breast lump. The youngest patient was 16 years of age and the eldest was 70 years of age [Table -1]. Maximum number of cases were seen in 15-25 years age group followed by 26-35 years age group.

Results of sonomammogram according to BIRADS score is given in Table -2. There were no patients in categories 0,1 and 6 .There were 14 patients (28\%) in category 2 revealing benign findings , 16 patients (32\%) in category 3 revealing probably benign finding , 10 in category $4(20 \%)$ revealing suspicious abnormality and 10 patients in category 5 $(20 \%)$ indicating a high suspicion of malignancy. Findings were considered benign if score was 2 or 3 and malignant if score was 4 or 5 . Sonomammography diagnosed $60 \%$ cases as benign and $40 \%$ cases as malignant.

Distribution of cases on FNAC and Histopathological examination are given in Tables- 3 and 4. On FNAC, 32 cases were diagnosed as benign with majority being Fibroadenomatoid hyperplasia and Fibroadenoma (12 cases each) and 18 cases were diagnosed as malignant. On histopathological follow up, 32 cases were diagnosed as benign with majority being Fibroadenoma (15 cases) 
and 18 cases as malignant with majority being Infiltrating ductal carcinoma (10 cases) followed by Infiltrating Lobular carcinoma (3 cases).

Four cases were given a score of 4 on BIRADS i.e., suspicious of malignancy of which 3 was diagnosed as Acute suppurative mastitis on FNAC and later on confirmed on histopathological examination as Fibrocystic disease with mastitis. The remaining case was diagnosed as Fibroadenoma / Intraductal papilloma on FNAC and as Intraductal Papilloma on Excision. These cases thus constituted the false positives in our study. Two cases were given a score of 3 i.e., probably benign on imaging, of which one was diagnosed as Atypical ductal hyperplasia and the other as Ductal carcinoma in situ. Both were later confirmed as Infiltrating ductal carcinoma on histopathological examination. These cases constituted the false negatives in our study.

Tables -5 and 6 (Figure 1- a, b, c and Figure 2- a, b, c) show the comparison of BIRADS scoring and FNAC with histopathologic findings respectively. The sensitivity, specificity, positive predictive value, negative predictive value and accuracy was $88 \%, 87.5 \%, 80 \%, 93 \%$ and $88 \%$ respectively for BIRADS score and $100 \%$ for all the parameters on FNAC. Table- 7 shows the overall accuracy of sonomammography using BIRADS scoring and FNAC in the diagnosis of breast lesions.

Table 1: Age Distribution of Cases

\begin{tabular}{|c|c|c|}
\hline Age Group & Number of Cases & Percentage \\
\hline $15-25$ & 17 & $34 \%$ \\
\hline $26-35$ & 13 & $26 \%$ \\
\hline $36-45$ & 9 & $18 \%$ \\
\hline $46-55$ & 3 & $6 \%$ \\
\hline $56-65$ & 5 & $10 \%$ \\
\hline $66-75$ & 3 & $6 \%$ \\
\hline Total & $\mathbf{5 0}$ & $\mathbf{1 0 0 \%}$ \\
\hline
\end{tabular}

Table 2: Distribution of benign and malignant lesions on Sonomammogram

\begin{tabular}{|c|c|c|}
\hline $\begin{array}{l}\text { SONOMAMMOGRAPHIC DIAGNOSIS } \\
\text { (BIRADS) }\end{array}$ & NUMBER OF CASES & PERCENTAGE \\
\hline BENIGN (BIRADS SCORE -2 and 3) & 30 & $60 \%$ \\
\hline MALIGNANT (BIRADS SCORE -4 and 5) & 20 & $40 \%$ \\
\hline TOTAL & 50 & $100 \%$ \\
\hline
\end{tabular}

Table 3: Distribution of lesions on FNAC

\begin{tabular}{|l|c|}
\hline LESIONS & NUMBER OF CASES \\
\hline BENIGN & 12 \\
- Fibroadenoma & 1 \\
- Fibroadenoma /Intraductal papilloma & 12 \\
- Fibroadenomatoid hyperplasia & 2 \\
- Breast abscess & 1 \\
- Intraductal papilloma & 1 \\
- Acute suppurative mastitis & 3 \\
\hline TOTAL & $32(64 \%)$ \\
\hline MALIGNANT & 7 \\
- Carcinoma breast & 2 \\
- Carcinoma probably medullary type & 1 \\
- Carcinoma -Infiltrating ductal /lnvasive Papillary Carcinoma & 4 \\
- DCIS & 1 \\
- Malignant phyllodes & 1 \\
- Apocrine carcinoma & 1 \\
- Infiltrating ductal & 1 \\
- Atypical ductal hyperplasia & 18 (36\%) \\
\hline TOTAL & 1 \\
\hline
\end{tabular}


Table 4: Distribution of lesions on Histopathology (Excision/Mastectomy)

\begin{tabular}{|c|c|c|}
\hline LESIONS & NUMBER OF CASES & PERCENTAGE \\
\hline $\begin{array}{ll}\text { BENIGN } \\
\text { - } & \text { Fibroadenoma } \\
\text { - } & \text { Fibroadenomatoid hyperplasia } \\
\text { - } & \text { Fibroadenoma with cystic change } \\
\text { - } & \text { Fibroadenomatoid hyperplasia with cystic change } \\
\text { - } & \text { Fibrocystic disease with mastitis } \\
\text { - } & \text { Intraductal papilloma }\end{array}$ & $\begin{array}{l}15 \\
7 \\
3 \\
1 \\
4 \\
2\end{array}$ & \\
\hline TOTAL & 32 & $64 \%$ \\
\hline $\begin{array}{ll}\text { MALIGNANT } \\
\text { - } & \text { Infiltrating ductal carcinoma } \\
\text { - } & \text { Infiltrating lobular carcinoma } \\
\text { - } & \text { Medullary carcinoma } \\
\text { - } & \text { Colloid carcinoma } \\
\text { - } & \text { Malignant phyllodes } \\
\end{array}$ & $\begin{array}{c}10 \\
3 \\
2 \\
2 \\
1\end{array}$ & \\
\hline TOTAL & 18 & $36 \%$ \\
\hline TOTAL & 50 & $100 \%$ \\
\hline
\end{tabular}

Table 5: Comparison of BIRADS score with Histopathology

\begin{tabular}{|l|c|c|c|}
\hline $\begin{array}{l}\text { SONOMAMMOGRAM } \\
\text { (BIRADS score) }\end{array}$ & \multicolumn{2}{|c|}{$\begin{array}{c}\text { HISTOPATHOLOGY } \\
\text { BENIGN MALIGNANT }\end{array}$} & TOTAL \\
\hline BENIGN & $\begin{array}{c}28 \\
(\mathrm{TN})\end{array}$ & 2 & 30 \\
\hline MALIGNANT & 4 & 16 & 20 \\
TOTAL & (FP) & $\mathbf{1 7}$ & 2 \\
\hline
\end{tabular}

Table 6: Comparison of FNAC with histopathology

\begin{tabular}{|l|c|c|c|}
\hline \multirow{2}{*}{ FNAC } & \multicolumn{2}{|c|}{$\begin{array}{c}\text { HISTOPATHOLOGY } \\
\text { BENIGN MALIGNANT }\end{array}$} & TOTAL \\
\hline BENIGN & 32 & 0 & 32 \\
\hline MALIGNANT & $(\mathrm{TN})$ & 18 & 18 \\
\hline TOTAL & 0 & $(\mathrm{FN})$ & \\
\hline
\end{tabular}

Table 7: Overall accuracy of FNAC and Sonomammography in breast lesions

\begin{tabular}{|l|c|c|}
\hline & FNAC & $\begin{array}{c}\text { SONOMAMMOGRAM } \\
\text { (BIRADS Score) }\end{array}$ \\
\hline Sensitivity & $100 \%$ & $88 \%$ \\
\hline Specificity & $100 \%$ & $87.5 \%$ \\
\hline Positive predictive value & $100 \%$ & $80 \%$ \\
\hline Negative predictive value & $100 \%$ & $93 \%$ \\
\hline Accuracy & $100 \%$ & $88 \%$ \\
\hline
\end{tabular}




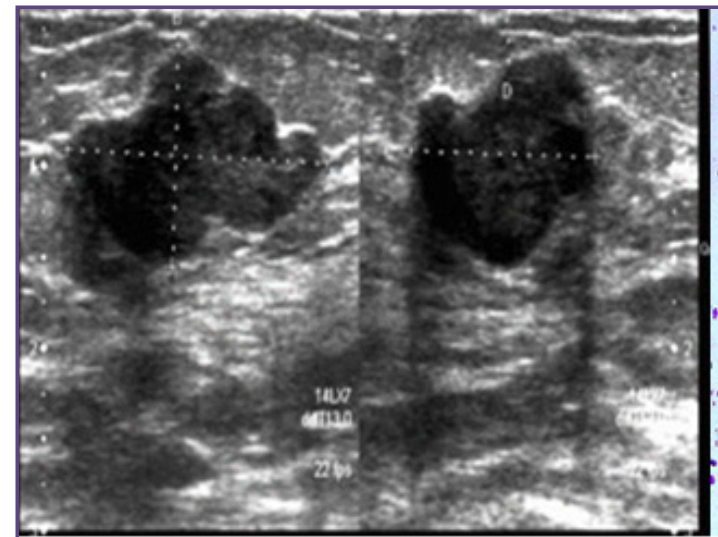

(a)

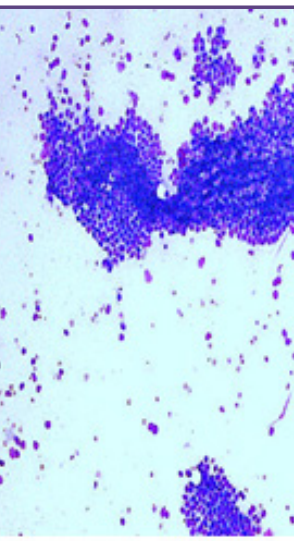

(b)

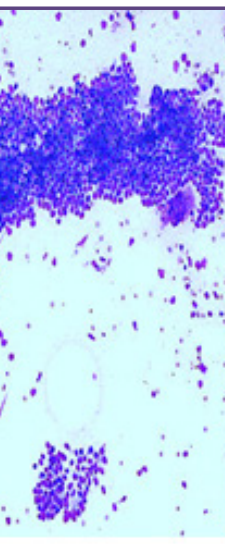

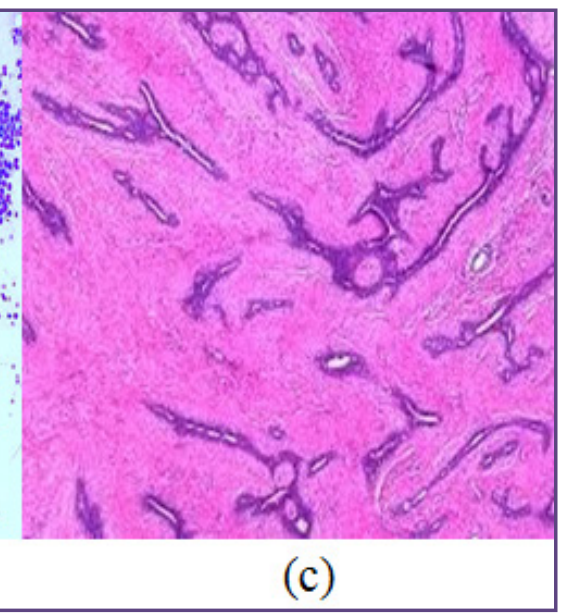

(c)

Fig. 1: (a) Breast ultrasound image of a solid lesion-BIRADS Category 3, (b) FNAC of the same case showing cell rich smear of elongated, branching fragments of ductal epithelial cells (H\&E,10x) (c) Excision biopsy showing compressed ducts having a linear branching pattern with slit-like lumens- Fibroadenoma( H\&E, 10x).

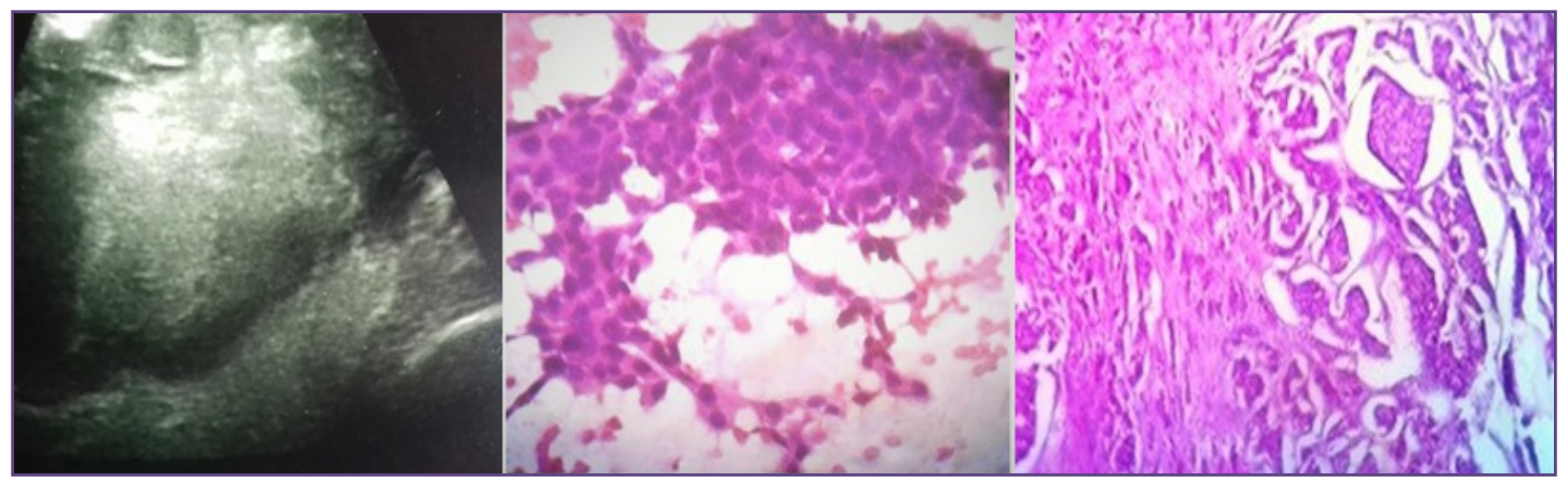

Fig. 2: (a) BIRADS category 5 lesion-well defined horizontally ovoid lobulated predominantly hypoechoic mass. (b) FNAC showing large neoplastic cells having pleomorphic hyperchromatic nuclei (H\&E,100x) (c) Histopathology showing neoplastic Invasive Ductal carcinoma in glandular pattern, sheets and clusters (H\&E, 100x).

\section{Discussion}

Breast diseases are common in females. In developing countries like India, females are unaware of breast pathologies and are hesitant to reveal, hence they are detected usually in advanced stages. Various benign breast lesions like fibroadenomas, breast abscess, galactocele, duct ectasia, enlarged lymph nodes and different malignancies are common pathologies of female breast. ${ }^{[9]}$

Patients with palpable breast lesions commonly present for radiology evaluation. Mammography is a primary method of detection and diagnosis of breast disease with sensitivity of $85 \%-95 \%$. But the false negative findings in mammography in evaluation of palpable breast mass is high, estimated between $4 \%$ \& $12 \% .{ }^{[9]}$ The BIRADS lexicon was first developed in 1993 for reporting mammography. Since its establishment, several studies have found that it can be helpful to physicians in predicting the likelihood of cancer. Although mammography is recognized as the best method of screening for breast cancer, breast sonography is now well-established as a valuable imaging technique, and, while there has been some controversy regarding its utility in evaluating solid breast masses for the likelihood of malignancy, several studies have suggested that sonographic appearance can be useful in differentiating malignant from benign solid breast masses. ${ }^{[10]}$

A wide variation in the sensitivity of sonomammogram in the diagnosis of breast lesions ranging from $67 \%$ to $97 \%$ have been reported.$^{[1]}$ In a study conducted by Shrestha M K et al the sensitivity and specificity of sonomammography in differentiating benign from malignant lesions using the BIRADS score was 78.9 and $95 \%$ respectively. ${ }^{[1]}$ Shumaila $\mathrm{S}$ M et al in their study have reported mammography to be positive in 66(90\%) and sonomammography to be positive in $68(93 \%)$ out of 
73 cases . ${ }^{[12]}$ Ultrasonography can be used to differentiate benign from malignant lesions with negative predictive value of $99.5 \%$, specificity of $67.8 \%$ and over all accuracy of $72.9 \%$ in a study according to Stavros et al. ${ }^{[13]}$ Emine D et al did a study on 546 breast lesions with histopathology analysis, they reported sensitivity and specificity for sonomammogram to be 72.6 and $88.5 \% .^{[14]}$ In the present study we got comparable results with a sensitivity of $88 \%$, specificity $87.5 \%$,positive predictive value of $80 \%$, negative predictive value of $93 \%$ and an accuracy of $88 \%$ in differentiating benign from malignant masses in sonomammography using the BIRADS lexicon system.

FNAC of breast lumps is an accepted and established method for determining the nature of breast lumps with a high degree of accuracy. Application of Fine Needle Aspiration for the diagnosis of palpable breast masses was first introduced by Martin and Ellis in 1930 and since then, it has been established as an important tool in the evaluation of breast lesions. Most of the patients with breast lumps are in a state of anxiety. So, in reducing anxiety and unnecessary surgical procedures as well as in minimization of delay in the diagnosis, FNAC proves very fruitful. FNA procedure is a safe method with only a few reported complications. ${ }^{[15]}$

In the present study, 18 and 32 cytologically diagnosed malignant and benign cases were confirmed as malignant and benign respectively on subsequent histopathological examinations. So, in our study, a $100 \%$ cytohistopathological correlation was observed for breast lesions. Zhang Qin et al in their study similarly reported a 97.1 and $97.3 \%$ sensitivity and specificity respectively for FNAC in diagnosing breast lesions . ${ }^{[16]}$ Tiwari $M$ has also observed the similar results in their studies with a sensitivity of $83.3 \%$ and specificity of $100 \%{ }^{[17]}$ The sensitivity, specificity, accuracy, negative predictive value, and the positive predictive value of FNAC was $98 \%, 100 \%, 98 \%$, $100 \%$, and $97 \%$, respectively in the study conducted by Bukhari et al. ${ }^{[18]}$ Our study showed higher values than the range reported with $100 \%$ sensitivity, specificity, positive and negative predictive values and accuracy.

FNAC is not only useful in diagnosis and further planning of treatment without need for biopsy, but also helpful in prognostication of the tumor factors such as nuclear grading, mitotic index, hormone receptor status and DNA contents. ${ }^{[19]}$ Histopathological examination should be performed for uncertain diagnostic cases and when the evaluation of the invasiveness or histological type of breast lesion is mandatory. ${ }^{[20]}$ The gold standard test used in our study was the histopathological report which is valid, reproducible and has been accepted as the gold standard internationally. For a good study, the reference test against which the diagnostic test in evaluation is compared should be gold standard. ${ }^{[1]}$

\section{Conclusion}

Ultrasonography with BIRADS score is an imaging technique and FNAC a tissue diagnostic technique. Both these diagnostic tools should be considered complimentary. The results of our study showed FNAC of breast lumps to be a reliable method to diagnose breast lump with high accuracy compared to sonographic categorization using BIRADS score. Considering patient's comfort, lack of requirement of anesthesia, rapid analysis and reporting and an absence of false positive results, FNAC could be considered an ideal initial diagnostic modality in breast lumps recognized by means of imaging techniques. Further advancement in the technique of both these procedures like FNAC under imaging guidance, addition of immunohistochemistry in cytology and addition of Doppler in USG may increase their accuracy. However all clinically malignant or suspicious masses should be subjected to histopathological examination which is the gold standard for tissue diagnosis.

\section{Reference}

1. Shrestha MK, Ghartimagar D, Ghosh A, Shrestha E, Bolar P. Significance of quadruple assessment of breast lump A Hospital based study. Journal of Pathology of Nepal. 2014;4:630-4.

2. Lalchan S, Thapa M, Sharma P, Shrestha S, Subash K, Pathak $\mathrm{M}$ et al. Role of Mammography Combined with Ultrasonography in Evaluation of Breast Lump. American Journal of Public Health Research. 2015;3(5A):95-8.

3. Chairat R, Puttisri A, Pamarapa A, Samintharapanya S, Tawichasri C, Patumanod J. Are Both Ultrasonography and Mammography Necessary for Cancer Investigation of Breast Lumps in Resource-Limited Countries? ISRN Oncology. 2013;Article ID 257942, doi:10.1155/2013/257942.

4. Arsalan F, Subhan A, Rasul S, Jalali U, Yousuf M, Mehmood $Z$ et al. Sensitivity and specificity of BI-RADS scoring system in carcinoma of breast. Journal of Surgery Pakistan. 2010;15(1):38-43. Phurailatpam J, Sakalecha A, Prasad CS, Kumar BN, Hegde P. Evaluation Of

5. Mammography, Sonomammography In Correlation With Fine Needle Aspiration Of Breast Lumps. Int J Biol Med Res. 2014;5(3):4370-6.

6. Quershi S A, Rehman K, Muhammad D, Khan M I, Jaffra H. Validity of Mammogram according to Bi-RADS Scoring In Relation with Histopathology among Females Presenting with Clinically Palpable Breast lump or Nipple discharge. Ann Pak Inst Med Sci. 2014;10(3):150-4.

7. Daramola AO, Odubanjo MO, Obiajulu FJ, Ikeri NZ. Correlation between Fine needle aspiration cytology and histology for palpable breast masses in a Nigerian tertiary 
health institution. International Journal of breast Cancer. 2015;Article ID 742573, doi:10.1155/2015/742573.

8. Yalavarthi S, Tanikella R, Prabhala S, Tallam US. Histopathological and cytological correlation of tumors of breast. Medical Journal of Dr. D.Y. Patil University. 2014;7 (3):326-31.

9. Taori K, Dhakate S, Rathod J, Hatgaonkar A, Disawal A, Wavare P et al. Evaluation of Breast Masses Using Mammography and Sonography as First Line Investigations. Open Journal of Medical Imaging. 2013;3:40-49.doi. org/10.4236/ojmi.2013.31006.

10. Heinig J, Witteler R, Schmitz R, Kiesel L, Steinhard J. Accuracy of classification of breast ultrasound findings based on criteria used for BI-RADS. Ultrasound Obstet Gynecol. 2008;32:573-78.

11. TakhellambamYS, Lourembam SS, Sapam OS, Kshetrimayum RS, Thoujam BS, Khan T. Comparison of Ultrasonography and Fine Needle Aspiration Cytology in the Diagnosis of Malignant Breast Lesions. Journal of Clinical and Diagnostic Research. 2013;7(12):2847-50.

12. Shumaila SM, Tayyiba A, Safdar AM. Mammographic Sonographic co-relation in the diagnosis of breast lump. Biomedica. 2008;24:147-51.

13. Stavros AT, Thickman D, Rapp CL, Dennis MA, Parker SH, Sisney GA. Solid Breast Nodules: Use of Ultrasonography to Distinguish between Benign and Malignant Lesions. Radiology. 1995;196(1):123-34.
14. Emine D, Suzana M, Halit Y, Arben K. Comparative accuracy of mammography and ultrasound in women with breast symptoms according to age and breast density. Bosn J Basic Med Sci. 2009;9:131-6.

15. Vala MT, Goswami A, Suri SK. Comparative study of cytological and histopathological finding in breast lesion. IOSR Journal of Dental and Medical Sciences. 2014;13(7):05-07.

16. Qin Z, NieShigui, Yuhua C, Limei Z. Fine Needle Aspiration Cytology of Breast Lesions: Analysis of 323 Cases. The Chinese-German Journal of Clinical Oncology. 2004;3(3):172-4.

17. Tiwari M. Role of FNAC in diagnosis of breast lumps. Kathmandu University Medical Journal. 2007;5:215-17.

18. Bukhari MH, Arshad M, Jamal S, Niazi S, Bashir S, Bakhshi IM. Use of fine-needle aspiration in the evaluation of breast lumps. Patholog Res Int. 2011;doi:10.4061/2011/689521

19. Velu ARK, Srinivasamurthy BC, Rani J. Cytological evaluation of benign breast lesions with histopathological correlation. Indian Journal of Pathology and Oncology. 2016;3(1):7-10.

20. Moschetta M, Telegrafo M, Carluccio DA, Jablonska JP, Rella L, Serio G et al. Comparison between fine needle aspiration cytology (FNAC) and core needle biopsy (CNB) in the diagnosis of breast lesions. G Chir. 2014;35(7/8):171-6.

*Corresponding author:

Dr Navya B N, Associate Professor, Department of Pathology, K V G Medical College and Hospital, Kurunjibhag, Sullia, D.K District- 574327,Karnataka, India Phone: +91 9886687911

Email: navyabn@rediffmail.com

Date of Submission : 25.10.2016

Date of Acceptance : 09.03.2017

Financial or other Competing Interests: None.

Date of Publication : 04.06.2017 